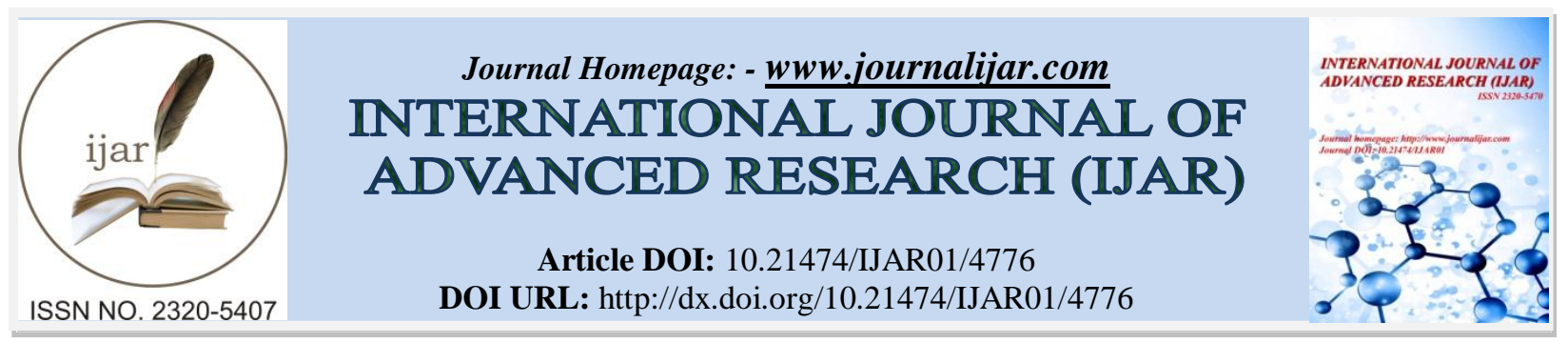

RESEARCH ARTICLE

\title{
SCREENING AND EVALUATION OF ANTIBACTERIAL SUBSTANCES FROM BACTERIAL CULTURES OF INDO-GANGETIC PLAINS.
}

Priyanka and Chandrawati Jee.

Department of Biotechnology, A.N. College, Patna.

\section{Manuscript Info}

Manuscript History

Received: 7 May 2017

Final Accepted: 9 June 2017

Published: July 2017

Key words:-

Antibacterial property, Zone of inhibition, Sonicated, Resistance, Bacteria, Indo-gangetic Plain.

\section{Abstract}

Resistance to Drug in various pathogenic and non pathogenic bacteria has been found to be increasing. To overcome this problem there is a dire need to search for new antibacterial compounds from various sources. With this perspective in mind bacterial isolates from four different sites of Indo-gangetic plain soils were tested. These bacterial cultures were isolated and assayed for their antibacterial compounds produced and tested their efficacy on three test system (Escherichia. coli, Staphylococcus aureus and Klebsiella pneumonia). The sonicated sample of the isolates as well as supernatant was used for this purpose to evaluate antibacterial property. Mass cultures of isolates were centrifuged to get the bacterial cell pellet and supernatant. Out of ten selected bacterial isolates, nine exhibited inhibitory activity against the test organisms. The zone of inhibition generated during this study has been noticed in the range of $0.9 \mathrm{~cm}$ to $1.6 \mathrm{~cm}$ on Klebsiella pneumonia, $1.2 \mathrm{~cm}$ to $1.5 \mathrm{~cm}$ on Escherichia coli and 0.95 to 1.3 on Staphylococcus aureus. Therefore, it is suggestive that Indo gangetic soil could be an interesting source to explore bacteria having unique feature of producing antibacterial compounds and this may be utilized for commercial value.

Copy Right, IJAR, 2017,. All rights reserved.

\section{Introduction:-}

The Indo Gangetic plain is a great alluvial crescent stretching from the Indus river system in Pakistan to the Punjab plain of India and the Ganga river system from Haryana plain to the delta of the Ganga in Bangladesh. Topographically the plain is homogeneous with only flood plain bluffs. Soils of Indo-gangetic plain are highly rich in gram +ve, free living and saprophytic bacteria [ Rahman et.al. 2011].These soil bacteria are reported as richest source of secondary metabolites which can be used as antibiotics after screening which can fight against several diseases. Out of 22,500 biologically active compounds that have obtained from microbes, $45 \%$ are produced by actinomycetes, $38 \%$ by fungi and $17 \%$ by unicellular bacteria [Berdy et.al. 2005].

Although, thousands of antibiotics have been isolated from soil bacteria, this represents only a small fraction of the repertoire of bioactive compounds produced [Zhao et.al. 2006]. Therefore, isolation of new soil bacteria from Indogangetic plain and characterization of their secondary metabolites is a valuable endeavor.

During present study, isolation of different soil bacteria from Indo gangetic plain in Bihar region has been done to characterize for their antibacterial efficacy. 
As the frequency of novel bioactive compounds obtained from terrestrial Actinobacteria decreases with time, Actinobacteria from diverse environments have been increasingly screened for their ability to produce new secondary metabolites. In the recent years, terrestrial and marine microorganisms have known for antimicrobial, antiviral, antitumor, anticoagulant, antidiabetic and cardio active properties. Antibiotic effect of actinomycetes has been used in many fields including agriculture, veterinary and pharmaceutical industry. Polypeptide antibiotics which constitute the actinomycetes have been gaining importance as a result of studies. Compounds that eliminate or inhibit the growth of bacteria, fungi and viruses are called antimicrobial (Betina, 1983).

The classification of actinomycetes was originally based largely upon the morphological observations. So, morphology is still an important characteristic for the description of taxa and it is not adequate in itself to differentiate between many genera. In fact, it was the only characteristic which was used in many early descriptions, particularly of Streptomyces species in the first few editions of Bergey's Manual. These observations are best made by the variety of standard cultivation media. Several of the media suggested for the International Streptomyces Project and by Pridham et al., (1957) have proven to be useful in our hands for the characterization of strains accessioned into the ARS.

\section{Material and Methods:-}

Collection of soil sample:- soil samples were collected 8 inches to 12 inches below the upper soil level in pre sterilized poly bag from four different sites of Indo gangetic plains lying in Bihar. These samples were dried in hot air oven at $50^{\circ} \mathrm{c}$ for $3 \mathrm{hrs}$. and then stored at $4^{\circ} \mathrm{c}$.

Table 1:- location of sites and depth from where sample is collected.

\begin{tabular}{|c|c|c|c|}
\hline Name of sites & Depth of sample in inch & Latitude & Longitude \\
\hline Barh & 11 & $25.42^{\prime} \mathrm{N}$ & $85.68^{\prime} \mathrm{E}$ \\
\hline Bakhtiyarpur & 9 & $25.28^{\prime} \mathrm{N}$ & $85.31^{\prime} \mathrm{E}$ \\
\hline Baily road, Patna & 8 & $25.61^{\prime} \mathrm{N}$ & $85.17^{\prime} \mathrm{E}$ \\
\hline Ashok Rajpath, Patna & 12 & $25.60^{\prime} \mathrm{N}$ & $85.08^{\prime} \mathrm{E}$ \\
\hline
\end{tabular}

\section{Culture media used:-}
a) Nutrient agar
b) Starch-casein Agar
c) Actinomycetes isolating Agar

\section{Method of plating:-}

Soil sample was collected and oven dried $50^{\circ} \mathrm{c}$ for $3 \mathrm{hrs}$ and then a pinch of this sample was transferred to normal saline to obtain a stock of inoculums. This was suitably diluted to obtain desired number of bacterial colony.

\section{Morphological examination of isolated bacteria:- Gram staining:-}

A thin smear glass slide was made using one drop of liquid broth culture of purified colony. This smear is then covered by crystal violet stain for $45 \mathrm{sec}$ and then washed off with water. Again gram's iodine is applied on smear for $45 \mathrm{sec}$ and then decolorized using alcohol and again washed off with water. Counter staining is done by safranin for 2 minutes. After washing and drying slides are viewed in 100X phase contrast microscope.

\section{Morphological characterization:-}

Fresh culture of actinomycetes were inoculated on ISP1 to ISP7 and incubated on $34 \mathrm{oC}$ for 5 days. Then colonies were examined on high magnification for study of their color, nature of colony mycelium, branching and aerial.

\section{Biochemical Characterization:-}

After preliminary studies colonies are tested for their carbon and nitrogen utilization. The ability of different bacterial strains in utilizing various carbon and nitrogen compounds as source of energy was studied by following the method recommended in International Streptomyces Project. Stock solution of 5sugars i.e., Xylose, Inositol, Sucrose, Raffinose, and Fructose having concentration of 10x was prepared in autoclaved water and sterilized by filtering through $0.22 \mathrm{~m}$ pore size. Similarly, Stock solution of nitrogen sources namely L-Aspergine, L-Arginine, Glysine, L-Histidine and L-Lysine having concentration of 10x was prepared in autoclaved water and sterilized by filtering through $0.22 \mathrm{~m}$ pore size membrane filters and all the stocks are stored at $4^{0} \mathrm{C}$.Media was prepared by 
adding $1 \%$ carbon source and $1 \%$ nitrogen source separately in sterile ISP2 medium. This media is then Inoculated and incubated at $28^{0 \mathrm{C}}$ for 7 to 10 days. Growth was observed by comparing them with positive and negative control.

\section{Culture purification and mass culturing for isolation of cell:-}

Each culture was transferred to $5 \mathrm{ml}$ of peptone water for purification in a sterile and capped tube and incubated overnight at $37^{\circ} \mathrm{c}$. This tube was considered as inoculums for mass culturing. These inoculums are again transferred to flasks with $250 \mathrm{ml}$ of peptone water and again incubated overnight at $37^{\circ} \mathrm{c}$ for $24 \mathrm{hrs}$. Under aseptic condition these cultures were transferred into centrifuge tube with proper naming done for each culture. These tubes were then centrifuged at $4000 \mathrm{rpm}$ for $15 \mathrm{~min}$ at low temperature. The supernatant fraction was also obtained to evaluate the presence of secondary metabolites. The pelleted fraction was sonicated in an ultra sonicator to obtain putative antimicrobial component in the cells.

\section{Auxanography to observe antibacterial Efficacy:-}

Auxanography was done using both culture supernatants and cell extract to evaluate the antibacterial effect on three different pathogenic bacteria viz. E.coli, S.aureus and K. pneumoniae. Auxanography was done against three positive control and one negative control. For positive control three very common drug for both Gram's positive and Gram's negative was used i.e. cefoxine, gentamicine, ampiciline. Normal saline was used for negative control. Out of ten selected bacterial culture nine isolates shows inhibitory activity against indicator bacteria

\section{Result and Discussion:-}

Bacteria act as source of chemicals which leads to the development of novel therapeutic agent to find against deadly diseases. Resistance of microorganism to existing antimicrobials is a serious problem and hence there is a need to discover unconventional antibiotics. The known bacterial culture being continuously exposed to a number of potentially toxic compounds, pollution and invaders, develop chemical defense systems to protect themselves. Possible contributes to the chemical defenses arise from multiple antimicrobial activities against Gram-positive and gram-negative bacteria and fungi. This suggestion is supported by the protease, amylase and cellulose activities found in bacteria. For instance, these enzymes can hydrolyze complex compounds such as proteins, lipids and carbohydrates of algae and micro-organism.

Among the different types of drugs prevailing in the market, antifungal antibiotics are a very small but significant group of drugs and have an important role in the control of mycotic diseases. Fungal infections have been gaining prime importance because of the morbidity of hospitalized patients (Beck-Sague and Jarvis, 1993). In particular, candidacies and aspergillosis have remained the opportunist fungal infections that occur most frequently. Presently, they represent a major area of concern in the medical field; however, the occurrences of invasive fungal diseases, particularly in AIDS and other immune compromised patients, are life-threatening and they increase economic burden (Beck-Segue and Jarvis, 1993; Talbot et al., 2006). The need for new, safe and more effective antifungal compounds are a major challenge to the pharmaceutical industry.

Many strains of bacteria which is yet unexplored would play a vital role in inhibiting the order of bacterial growth due community dynamics of the external micro flora. Secondary metabolites produced by these microbes can be screened, isolated, identified and purified using standard techniques.

Side effects of highly potential antibiotics have compelled the scientist to develop novel ways to ensure effective and efficient medicine which are eco-friendly both for human physiology and environment. Scientific and systematic information and data base on bacterial community are still scanty and very little. Therefore it is the need of hour to isolate, identify and characterized the new compounds derived from bacterial community to fulfill the gap in available information in the area of study.

On the basis of microscopic study of all ten Gram's stained slide following results have been observed and has been described in table -1 .

Table 1:- The taxonomical characterization of different isolated bacteria.

\begin{tabular}{|l|l|l|}
\hline S.no & Name of isolates & Observation \\
\hline 1. & NA PT $^{-1}(0)$ & Gram's -ve Diplobacillus \\
\hline 2. & NA PT $^{-1}(0)$ New & Gram's -ve Bacillus \\
\hline
\end{tabular}




\begin{tabular}{|c|c|c|}
\hline 3. & NA BL10-2(1) & Gram's +ve Coccus \\
\hline 4. & NA BL10-2 (2) & Gram's +ve Coccus \\
\hline 5. & $\mathrm{NA} \mathrm{BL10}^{-3}(1)$ & Gram's +ve Coccus \\
\hline 6. & NA BL10 ${ }^{-3}(2)$ & Gram's +ve Coccus \\
\hline 7. & AIA BR10 ${ }^{-3}$ & Gram's +ve Coccus \\
\hline 8. & AIA BT $\underline{M}$ & Gram's -ve Coccus \\
\hline 9. & NA BT $10^{-4}$ & Gram's +ve Coccus \\
\hline 10. & NA BK $10^{-4}$ & Gram's -ve Bacillus \\
\hline
\end{tabular}

Thus, above described isolates were selected for further studies.

To evaluate the antibacterial property of the isolates experiment was designed which has been described in table- 2 .

Table 2:- Auxanographic studies with different isolates.

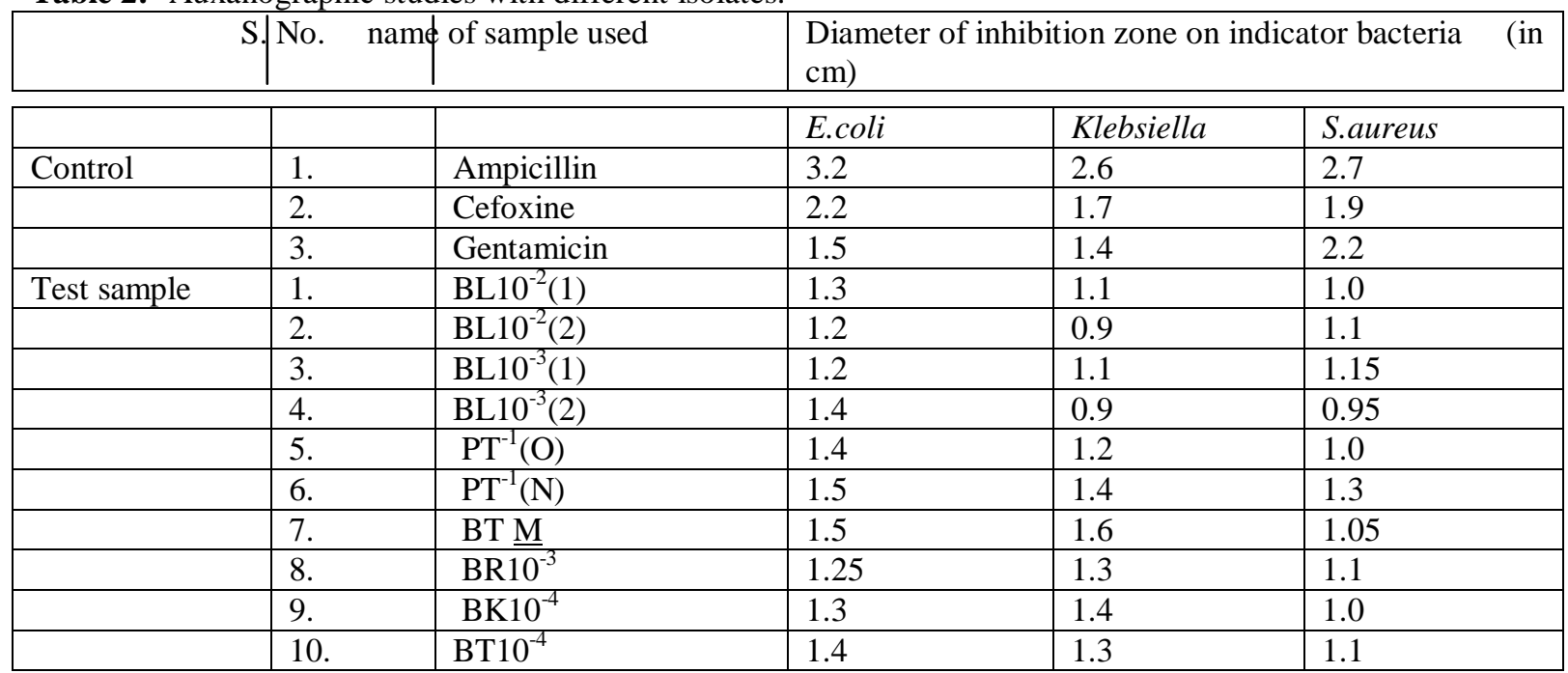

Table 3:- Assimilation of carbon sources by selected microbial Isolates

\begin{tabular}{|c|c|c|c|c|c|c|}
\hline Sr. No. & Name of isolates & \multicolumn{5}{|c|}{ Carbon Sources } \\
\hline & & Xylose & Inositol & Sucrose & Raffinose & Fructose \\
\hline 1. & BL10 $^{-2}(1)$ & - & $+/-$ & + & $+/-$ & $+/-$ \\
\hline 2. & BL10 $^{-2}(2)$ & + & - & - & - & - \\
\hline 3. & BL10 $^{-3}(1)$ & - & - & + & $+/-$ & - \\
\hline 4. & BL10 $^{-3}(2)$ & $+/-$ & $+/-$ & $+/-$ & - & - \\
\hline 5. & $\mathbf{P T}^{-1}(\mathbf{O})$ & $+/-$ & + & - & - & + \\
\hline 6. & $\mathbf{P T}^{-1}(\mathbf{N})$ & - & $+/-$ & + & + & $+/-$ \\
\hline 7. & BT $\underline{\underline{M}}$ & + & $+/-$ & + & $+/-$ & + \\
\hline 8. & BR10 $^{-3}$ & + & - & $+/-$ & $+/-$ & - \\
\hline 9. & BK10 $^{-4}$ & $+/-$ & - & - & - & - \\
\hline 10. & BT10 $^{-4}$ & $+/-$ & - & + & $+/-$ & + \\
\hline
\end{tabular}

Table 4:- Assimilation of Nitrogen sources by selected microbial Isolates

\begin{tabular}{|c|c|c|c|c|c|c|}
\hline Sr. No. & Name of isolates & \multicolumn{5}{|c|}{ Nitrogen sources } \\
\hline & & L Aspergine & L Arginine & Glysine & L Histidine & L Lysine \\
\hline 1. & BL10 $^{-2}(\mathbf{1})$ & + & - & - & - & + \\
\hline 2. & BL10 $^{-2}(\mathbf{2})$ & $+/-$ & $+/-$ & - & + & - \\
\hline 3. & BL10 $^{-3}(\mathbf{1})$ & $+/-$ & + & $+/-$ & - & $+/-$ \\
\hline 4. & $\mathbf{B L 1 0}^{-3}(\mathbf{2})$ & - & - & $+/-$ & + & $+/-$ \\
\hline 5. & PT $^{-1}(\mathbf{O})$ & - & $+/-$ & $+/-$ & $+/-$ & - \\
\hline 6. & PT $^{-1}(\mathbf{N})$ & - & - & + & $+/-$ & - \\
\hline 7. & BT $^{\mathbf{M}}$ & + & + & - & - & $+/-$ \\
\hline
\end{tabular}




\begin{tabular}{|c|c|c|c|c|c|c|}
\hline 8. & BR10 $^{-3}$ & + & + & - & $+/-$ & - \\
\hline 9. & BK10 $^{-4}$ & - & $+/-$ & $+/-$ & - & + \\
\hline 10. & BT10 $^{-4}$ & $+/-$ & - & - & + & $+/-$ \\
\hline
\end{tabular}

[Abbreviation of symbols used:

NA- Nutrient Agar, AIA- Actinomycetes Isolating Agar, BL- sample from Bailey Road; Patna, PT- sample from Krishna Ghats; Patna (here $\mathrm{O}$ and $\mathrm{N}$ represent two different sites), BT; BK- samples from two different site of Bakhtiyarpur, BR-sample from Barh, 10 ${ }^{\mathrm{x}}$ - no. of dilution factor.]

All the isolate exhibits sensitivity to different antibiotics. Since, resistance is a character of producing organism; hence the isolates were considered as potent source.

It appears that BTM in the range of dilution is the most potent and active isolated strain for the production of secondary metabolite, as it generates a zone of inhibition to the extent of $1.6 \mathrm{~cm}$ on the test organism Klebsiella pneumonia. The lowest potency of secondary metabolite synthesis was exhibited by strain BL (2) of both dilution factor $10^{-2}$ and $10^{-3}$ as it develops a zone of inhibition of $0.9 \mathrm{~cm}$ only on the test organism Klebsiella pneumonia.

\section{Conclusion:-}

On the basis of above studies it has been noticed that the isolates from Indo-gangetic soils having antibacterial property on different pathogenic bacteria viz. E.coli, S.aureus and K. pneumonia; the common disease causing agents in Indo-gangetic plain region. Out of ten selected bacterial culture nine isolates shows inhibitory activity against indicator bacteria having minimum inhibition zone of $0.9 \mathrm{~cm}$ and maximum inhibition zone of $1.6 \mathrm{~cm}$ on $K$. pneumonia. The zones of inhibition were recorded against E.coli and S.aureus also. Therefore, it is suggestive that Indo gangetic soil could be an interesting source to explore bacteria having antibacterial efficacy and may be utilized for commercial value.

\section{References:-}

1. Md. Ajijur Rahman, Md. Zahidul Islam and Md. Anwar Ul Islam, "Antibacterial Activities of Actinomycete Isolates Collected from Soils of Rajshahi, Bangladesh" Biotechnology Research International, vol 2011, pp. 6, 2011.

2. A. L. Demain and J. E. Davies, Mannual of Industrial Microbiology and Biotechnology, chapter-1, American Society of Microbiology, Washington, DC, USA, $2^{\text {nd }}$ edition, 1999.

3. J. Berdy, "Bioactive microbial metabolites: a personal view", Journal of antibiotics, vol. 58, no. 1, pp. 1-6, 2005.

4. H. Zhao, R. L. Parry, D. I. Ellis, G. W. Griffith and R. Good acre, "The rapid differentiation of Streptomycin isolates using Fourier transform infrared spectroscopy", Vibrational Spectroscopy, vol. 40, no. 2, pp. 213-218, 2006.

5. J. Berdy," Are Actinomycetes exhausted as a source of secondary metabolites?" proceedings of the $9^{\text {th }}$ Symposium Actinomycetes, pp. 13-34, 1995.

6. M. Arifuzzaman, M. R. Khatun, and H. Rahman,"'Isolation and screening of Actinomycetes from Sundarbans soil for antibacterial activity", African journal of Biotechnology, vol. 9, no. 29, pp. 4615-4619, 2010.

7. M. G. Watve, R. Tickoo, M. M. Jog and B. D. Bhole, "How many antibiotics are produced by the genus Streptomyces?", Archives of Microbiology, vol. 176, no. 5, pp. 386-390, 2001. 1. Bhaskaran R, Vijayakumar R and Mohan PM. Enrichment method for the isolation of bioactive actinomycetes from mangrove sediments of Andaman Islands, India. Malaysian Journal of Microbiology 2011; 7(1), pp. 26-32.

8. Ramesh S, Mathivanan N. Screening of marine actinomycetes isolated from the Bay of Bengal, India for antimicrobial activity

9. and industrial enzymes. World J. Microbiol.Biotechnol 2009; 25:2103-2011.

10. Good fellow M and ST Williams. Ecology of actinomycetes.Annu.Rev. Microbiol 1983; 37: 189-216.

11. Bredholt H, Fjaervik E, Jhonsen G and Zotechev SB. Actinomycetes from sediments in the TrondheinFjrod, Norway: Diversity and biological activity. Journal of Marine Drugs 2008; 6: 12-24.

12. Solingen VP, Meijer D, Kleij WA, Branett C, Bolle R, Power SD, Jones BE. Cloning and expression of an endocellulase gene from a novel Streptomyces isolated from an East African soda lake. Extremophiles 2001; 5: 333-341. 
13. Goshev I, Gousterova A, VasilevaTonkova E, Nedkov P. Characterization of the enzyme complexed produced by two newly isolated thermophilicactinomycete strains during growth on collagen rich materials. Process Biochem 2005; 40:1627-1631.

14. Prabavathy VR, Mathivanan N, Murugesan K. Control of blast and sheath blight diseases of rice using antifungal metabolites produced by Streptomyces sp. PM5. Biol Control 2006; 39:313-319.

15. Haritha R, Sivakumar K, Jagan Mohan YSYV and Ramana T. Amylolytic and ProteolyticActinobacteria Isolated from Marine Sediments of Bay of Bengal. International Journal of Microbiological Research 2010; 1(2): 37-44.

16. Kim CM, Lec KH, Kwon OS, Shimazu A and Yoo ID. Selective isolation of Actinomycetes by physical pretreatment of soil sample. Journal of Applied Environmental Microbial Biotechnology 1994; 22: 222-225.

17. Wellington EMH and Cross T. Taxonomy of antibiotic producing Actinomycetes and new approaches to their selective isolation. In: "Progress in industrial microbiology?" Bushel, M. E. (Eds.). Elsevier, Amsterdam 1983; pp: 36. 